\title{
Review
}

Basic Research

Diabetes Metab J 2020;44:658-667

https://doi.org/10.4093/dmj.2019.0220

pISSN 2233-6079 · eISSN 2233-6087

DIABET\&S \& METABOLISM JOURNAL

\section{Revisiting the Bacterial Phylum Composition in Metabolic Diseases Focused on Host Energy Metabolism}

\author{
Yeonmi Lee ${ }^{1}$, Hui-Young Lee ${ }^{1,2}$ \\ ${ }^{1}$ Laboratory of Mitochondrial and Metabolic Diseases, Lee Gil Ya Cancer and Diabetes Institute, Gachon University, Incheon, \\ ${ }^{2}$ Division of Molecular Medicine, Department of Medicine, Gachon University College of Medicine, Incheon, Korea
}

Over a hundred billion bacteria are found in human intestines. This has emerged as an environmental factor in metabolic diseases, such as obesity and related diseases. The majority of these bacteria belong to two dominant phyla, Bacteroidetes and Firmicutes. Since the ratio of Firmicutes to Bacteroidetes increases in people with obesity and in various animal models, it has been assumed that phylum composition causes the increase in occurrence of metabolic diseases over the past decade. However, this assumption has been challenged by recent studies that have found even an opposite association of phylum composition within metabolic diseases. Moreover, the gut microbiota affects host energy metabolism in various ways including production of metabolites and interaction with host intestinal cells to regulate signaling pathways that affect energy metabolism. However, the direct effect of gut bacteria on host energy intake, such as energy consumption by the bacteria itself and its effects on intestinal energy absorption, has been underestimated. This review aims to discuss whether increased ratio of Firmicutes to Bacteroidetes is associated with the development of metabolic diseases, and whether energy competition between the bacteria and host is a missing part of the mechanism linking gut microbiota to metabolic diseases.

Keywords: Energy metabolism; Etiology; Gastrointestinal microbiome; Intestinal absorption; Metabolic diseases

\section{INTRODUCTION}

"Microbiota" is used to refer to all microorganisms that inhabit the human body, including bacteria, fungi, protozoa, and viruses. Among these microorganisms, gut bacteria are the largest population of microbiota, and weigh roughly $1.5 \mathrm{~kg}$ of cells in human [1]. The human body carries approximately $3.9 \times$ $10^{13}$ bacterial cells, with the largest number of cells residing in the large intestine, with $10^{11}$ bacteria cells $\mathrm{g}^{-1}$ of wet stool $[2,3]$. Moreover, 10 million microbial genes have been identified in the human gut, and this number is over 100-fold higher than the number of genes in human genome [4]. The majority of bacteria belong to two dominant phyla, Bacteroidetes and Fir- micutes [2]. Since the ratio of Firmicutes to Bacteroidetes has increased in obese people and in various animal models [5], phylum composition has been considered to be a potential cause of metabolic disease over the past decade [6]. However, this assumption has been challenged by recent studies that have identified either no, or even a negative association between phylum composition and metabolic diseases in human studies [7-10].

Excessive energy accumulation in the host is a major common factor in metabolic disease pathogenesis (e.g., in obesity and type 2 diabetes mellitus) [11]. Considering that the number of bacterial cells in the human gut, it is not surprising that gut bacteria can alter host energy metabolism and affect meta-
Corresponding author: Hui-Young Lee (D) https://orcid.org/0000-0002-3464-6382 Lee Gil Ya Cancer and Diabetes Institute, Gachon University, 21 Namdong-daero 774beon-gil, Namdong-gu, Incheon 21565, Korea

E-mail: hylee@gachon.ac.kr
This is an Open Access article distributed under the terms of the Creative Commons Attribution Non-Commercial License (https://creativecommons.org/licenses/by-nc/4.0/) which permits unrestricted non-commercial use, distribution, and reproduction in any medium, provided the original work is properly cited. 
bolic disease pathogenesis. Indeed, many researchers have underlined the role of gut microbiota for host health. Furthermore, the gut microbiota has emerged as an important environmental factor for metabolic disease including obesity and type 2 diabetes mellitus $[6,12,13]$. Most of these studies have focused on the metabolites produced by bacteria (e.g., shortchain fatty acids [SCFAs] and bile acids) and the signaling pathways that can affect host energy metabolism. However, the direct effects of gut bacteria on host energy intake (e.g., energy consumption by bacteria themselves and its effects on intestinal energy absorption) have been greatly underestimated. Given that such a large number of bacteria live in the gastrointestinal tract $[2,3]$, it is surprising that the number of studies over the past 20 years regarding bacterial energy consumption and the effect on host energy harvest have been so few and far between. This is likely due to the long-held belief that the gut microbiota aids host energy harvest by breaking down indigestible carbohydrates into SCFAs that can be used as energy substrates by the host $[6,14]$. This energy harvest has been known to supply up to approximately $10 \%$ of daily calories when the diet is rich in fiber $[15,16]$. However, in today's world we have been faced with the Western diet which is low in fiber [17]. Therefore, it is doubtful whether SCFAs contribute to energy harvest in a meaningful way. Therefore, this review focuses on two issue, firstly, whether bacterial phylum composition is associated with metabolic disease and, secondly, whether energy competition between bacteria and host is another missing piece of the puzzle that is the mechanism(s) of metabolic diseases.

\section{COMPOSITION OF BACTERIAL PHYLUM AND METABOLIC DISEASES}

Until the late 1990s, the gut microbiota had mostly been studied for its role in influencing the mucosal immune system [18] and increasing energy harvest for the host [14,19]. In the early 2000s, Backhed et al. [20] linked the gut bacterial SCFAs to host energy harvest and suggested the increased ratio of Firmicutes to Bacteroidetes was associated with obesity in leptindeficient $(o b / o b)$ mice $[21,22]$. As followed Table 1, the altered composition of bacterial phylum has emerged as a factor which regulates the host metabolism [5,22-24], because germfree mice which were transplanted with cecal microbiota from

Table 1. Association between the bacterial phylum composition and metabolic disease in human and rodents

\begin{tabular}{|c|c|c|c|c|}
\hline Disease & $\begin{array}{l}\text { Ratio of Firmicutes to } \\
\text { Bacteroidetes }\end{array}$ & Description & Species & Reference \\
\hline \multirow[t]{7}{*}{ Obesity } & Increase & Increase of Bacillus class at the phylum Firmicutes in $o b / o b$ mice & Mouse & {$[22]$} \\
\hline & Increase & $\begin{array}{l}\text { Increase of Clostridiales at the phylum Firmicutes and decrease of } \\
\text { Bacteroidales at the phylum Bacteroidetes on high-fat diet }\end{array}$ & Mouse & {$[23]$} \\
\hline & Increase & Fecal microbiota of 12 obese people according to body-weight change & Human & {$[5]$} \\
\hline & Decrease & $\begin{array}{l}\text { Increase of family Prevotellaceae (most of genus Prevotella) at the phylum } \\
\text { Bacteroidetes in obese patients }\end{array}$ & Human & {$[30]$} \\
\hline & No association & No association with BMI & Human & {$[7]$} \\
\hline & No association & $\begin{array}{l}\text { Decrease of M. smithii and B. animalis but no association with Firmicutes } \\
\text { and obese }\end{array}$ & Human & {$[8]$} \\
\hline & No association & No relationship between the relative populations of gut microbiota and BMI & Human & [9] \\
\hline \multirow[t]{4}{*}{ NAFLD } & Increase & Decrease of Bacteroidetes in NASH patients with obesity $\left(\mathrm{BMI}>30 \mathrm{~kg} / \mathrm{m}^{2}\right)$ & Human & {$[24]$} \\
\hline & Decrease & $\begin{array}{l}\text { Decrease of SCFAs-producing bacteria at the phylum Firmicutes and } \\
\text { increase of LPS-producing bacteria in non-obese people with NAFLD }\end{array}$ & Human & {$[10]$} \\
\hline & Decrease & $\begin{array}{l}\text { Increase of genus Prevotella at the phylum Bacteroidetes and genus } \\
\text { Escherichia at the phylum Proteobacteria in NASH patients }\end{array}$ & Human & {$[30]$} \\
\hline & Decrease & Increase of Proteobacteria and decrease of Firmicutes with NAFLD & Human & {$[31]$} \\
\hline T1DM & Decrease & Increase of butyrate-producing bacteria in heathy people & Human & {$[32]$} \\
\hline T2DM & Decrease & Decrease of Clostridia class at the phylum Firmicutes in T2DM patients & Human & [33] \\
\hline
\end{tabular}

M. smithii, Methanobrevibacter smithii; B. animalis, Bifidobacterium animalis; NAFLD, non-alcoholic fatty liver disease; BMI, body mass index; NASH, non-alcoholic steatohepatitis; SCFA, short-chain fatty acid; LPS, lipopolysaccharide; T1DM, type 1 diabetes mellitus; T2DM, type 2 diabetes mellitus. 
obese mice, become obese [25]. Additionally, a series of publications support the association between bacterial phylum composition, obesity, and obesity-related metabolic diseases in a variety of animal models including in humans $[4,5]$ and pigs [26]. Gut microbial community affect to host energy metabolism via digestion of dietary nutrients, for instance, bacteria belonging to phylum Bacteroidetes possess a large number of carbohydrate-active enzyme (CAZyme) $[27,28]$. The derivatives by CAZyme-producing bacteria such as SCFAs can use energy sources in enterocyte and peripheral tissues; regulate gene expression of host's metabolism [16,29]. Thus, the association between obesity and bacterial phylum composition has emerged as a major factor underlying metabolic disease pathogenesis.

However, there are some of concerns regarding the old hypothesis of energy harvest and phylum composition in the pathogenesis of metabolic diseases. Recently there have been an increasing number of studies which have shown no association between phylum composition and obesity in human stool samples [7-9], and some studies even show an opposite association in patients with other major metabolic diseases, such as non-alcoholic fatty liver disease (NAFLD) [10,30,31], type 1 diabetes mellitus [32], and type 2 diabetes mellitus (Table 1) [33]. The ratio of Firmicutes to Bacteroidetes is decreased in NAFLD patients [10,30,31], in type 1 and the type 2 diabetes mellitus $[32,33]$. An intake of saccharin induces glucose intolerance in human and in mice, and associated with the decreased ratio of Firmicutes to Bacteroidetes and increased fecal SCFAs content [34]. Furthermore, Akkermansia muciniphila, a member of not Firmicutes nor Bacteroidetes but Verrucomicrobia, is related with reduced adiposity [35] and glucose homeostasis [36] in mice. Taken together, these studies suggest that at the phylum-level of bacterial composition does not consistently indicate the direction of metabolic diseases in animal and human studies in relation to metabolic diseases such as NAFLD and diabetes.

\section{THE EFFECT OF GUT MICROBIAL METABOLITES IN HOST ENERGY METABOLISM}

Gut bacteria can affect host energy metabolism via its microbial products and metabolites. In this section, we discuss how the gut microbiota and its metabolites affect host metabolism and diseases progression (Fig. 1).

\section{Short-chain fatty acids}

As mentioned previously, SCFAs produce metabolites by fermentation of carbohydrates. These metabolites include acetate, propionate, and butyrate $[6,14]$. Moreover, these SCFAs can influence host energy metabolism through the regulation of metabolic pathways or by directly used as an energy source after absorption into host's body [16]. In this section, we summarize the effect of respective SCFAs on the host energy metabolism. Firstly, the absorbed acetate suppresses weight gain and liver lipid accumulation under a high-fat diet, upregulating the gene expression of fatty acid oxidation through activating AMP-activated protein kinase/peroxisome proliferator-activated receptor $\alpha(\mathrm{AMPK} / \mathrm{PPAR} \alpha)$-pathway $[37,38]$. Acetate also inhibits lipid accumulation in adipose tissue through activating $\mathrm{G}$ protein-coupled receptor 43 (GPR43) [39]. Furthermore, acetate decreases the circulating-free fatty acids in plasma by regulating GPR43 in the host [40]. Secondly, the absorbed propionate in the liver raises hepatic glucose production and the tricarboxylic acid cycle [41]. Propionate fermented from soluble fiber activates intestinal gluconeogenesis (IGN) as a substrate of glucose and a gut-brain transmission axis via free fatty acid receptor 2 (FFAR2, also known as GPR43) in the portal vein. They confirmed that absence of IGN using intestinal glucose-6-phosphatase knockout mice is not effective for metabolic effect of soluble fiber [42]. Furthermore, propionate regulates host glucose homeostasis via induction of IGN [42]. Thirdly, butyrate increases skeletal muscle size, inducing transformation into oxidative fiber and mitochondrial function in mice. Moreover, the mice treated with butyrate also have increased adaptive thermogenesis in cold environments via stimulation of the AMPK-peroxisome proliferator-activated receptor gamma coactivator $1 \alpha$ (PGC-1 $\alpha)$ pathway, and the mice are protected from insulin resistance and high-fat dietinduced obesity $[43,44]$. It has also been reported that butyrate decreases the size of adipose tissue in mice by activating adrenergic $\beta 3$ receptor (AR $\beta 3$ ) and hormone-sensitive lipase (HSL) [45]. Together, the SCFAs which are gut microbiota-derived metabolites can regulate energy metabolism in several tissues in the host including liver, adipose tissue, skeletal muscle, and the brain (the specific part of brain will be discussed in the next section).

\section{Gut-brain axis: modulation of appetite}

Gut microbiota-derived metabolites can also contribute to modulation of appetite and satiety in the brain through regula- 


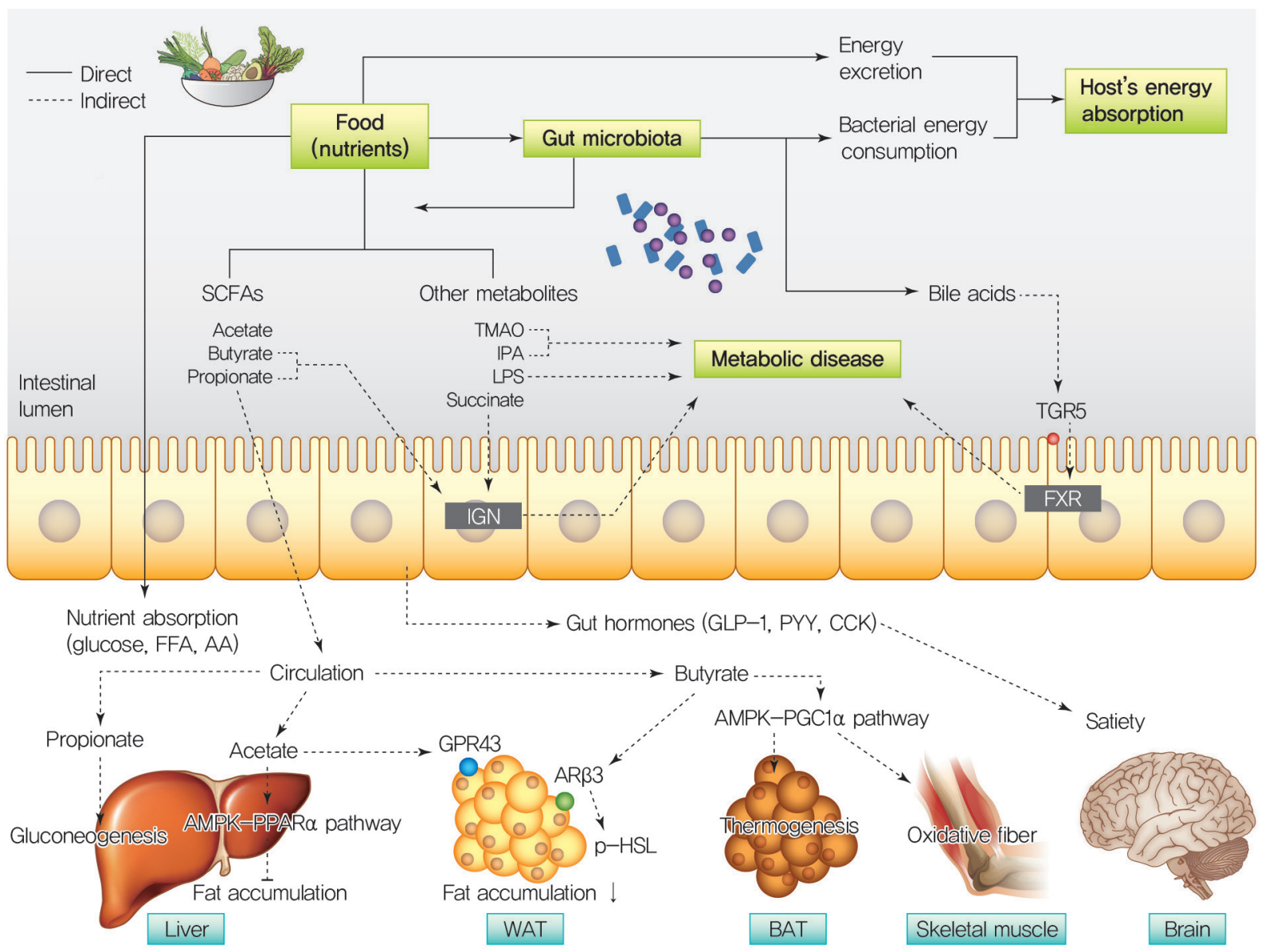

Fig. 1. Gut microbiota contribute to host energy absorption through the direct/indirect ways. Food intake alters the composition of the gut microbiota and the gut microbiota influences host energy absorption directly or indirectly while the nutrients are traveling in the intestine. The nutrients, which are obtained from a meal, undergo one of three routes during the digestive processes in the intestine, in face of energy metabolism, or the remains of them are excreted from the body. First, the nutrients such as carbohydrates, proteins, and lipids are digested and degraded with digestive enzymes and then absorbed into the host. Second, gut microbiota directly consume nutrients as their energy source. Lastly, the nutrients can be converted into metabolites such as shortchain fatty acids (SCFAs; acetate, butyrate, and propionate), trimethylamine $\mathrm{N}$-oxide (TMAO), and indole propionate (IPA) by the gut microbiota. The gut microbiota producing metabolites are absorbed and circulated in the host. Acetate reduces the fat accumulation by stimulating the AMPK-peroxisome proliferator-activated receptor a (PPARa) pathway and G-protein-coupled receptor 43 (GPR43) in the liver and white adipose tissue (WAT), respectively [37,38]. Butyrate induces intestinal gluconeogenesis (IGN) via cAMP signal and decreases hepatic fat accumulation by GPR43 and releases phosphorylated hormone-sensitive lipase (p-HSL) by adrenergic $\beta 3$ receptor (AR $\beta 3$ ). Moreover, butyrate activates thermogenesis in brown adipose tissue (BAT) and transformation to oxidative fibers in the skeletal muscle via the AMPK-peroxisome proliferator-activated receptor gamma coactivator $1 \alpha(\mathrm{PGCl} \alpha)$ pathway. Propionate, a precursor of glucose in tissues, stimulates IGN and hepatic gluconeogenesis. Gastrointestinal microbiome-producing SCFAs release gut hormones (glucagon like peptide-1 [GLP-1], peptide YY [PYY], cholecystokinin $[\mathrm{CCK}])$ from enteroendocrine cells by stimulating GPR43. The gut hormones regulate appetite and satiety. Besides producing SCFAs, the gut microbiota can also produce TMAO, which is a major risk factor of cardiovascular disease. The IPA, which is produced from tryptophan by the gastrointestinal microbiome, improves insulin secretion. Lipopolysaccharide (LPS), produced by gram-negative bacteria, promote metabolic disease thought induction of inflammation as an endotoxin. Succinate, which fermented from dietary fiber by gut bacteria, activates IGN, resulting improving metabolic disease such as glucose homeostasis. Additionally, gut microbiota can convert primary bile acids into secondary bile acids in the intestine. The bile acids bind G proteincoupled bile acid receptor 1 (TGR5) upon the enteroendocrine cell and function as farnesoid X receptor (FXR) agonist. FFA, free fatty acid; AA, amino acid. 
tion of several hormones [46]. These gut microbiota-derived metabolites can modulate the nervous network through afferent nerves and gut hormone secretion including peptide YY (PYY), glucagon like peptide-1 (GLP-1), and cholecystokinin (CCK) $[46,47]$. The gut microbiota-producing SCFAs can also modulate appetite and food intake via the gut-brain axis. Propionate stimulates PYY and GLP-1 secretion from primary human colonic cells in the human colon, and the gut hormones are known to enhance satiety and reduce appetite [48]. Acetate decreases energy intake through the regulation of appetite in the hypothalamus as well as the secretion of GLP-1 and PYY [49], but intestinal acetate can oppositely promote hyperphagia and obesity via gut microbiota-brain- $\beta$-cell axis [50]. Additionally, some strains of human gut microbiota can produce a neuroactive metabolite like $\gamma$-aminobutyric acid (GABA), the major inhibitory neurotransmitter, which is involved in hypothalamic appetite stimulation [46,51]. Enteroendocrine cell synapse in gut lumen is directly connected to brain within milliseconds and the neural circuit is transduced by a sugar stimulus, can regulate cumulative food intake in mice [52]. Furthermore, various pathways have been suggested how gut microbiota may alter brain and behavior, and reviewed in a recent paper focused on vagus nerve signaling [53]. Therefore, gut microbiota-producing metabolites can be a modulator of food intake through the gut-brain axis.

\section{Bile acid}

Bile acid is known to be facilitator for dietary lipid absorption, and can be converted into secondary bile acids by gut bacteria [54]. The concentration of bile acid in human stool is increased by a high-fat diet [55]. Moreover, cholic acid, which is the major component of primary bile acids, augments the ratio of Firmicutes to Bacteroidetes of cecal contents in rats [56]. Taken together, bile acid can be affected by the intestinal environment and can alter gut microbiota composition. Moreover, bile acids can regulate intestinal cell signaling by activating receptors such as G protein-coupled bile acid receptor 1 (TGR5) and farnesoid X receptor (FXR) [6], which can modulate host energy metabolism [57]. The regulation of intestinal signaling is considered to be an example of host lipid metabolism $[6,58]$ and the FXR agonist lowers plasma glucose levels by sensitization to insulin [59]. In addition, there is a publication that shows that energy expenditure is increased by bile acid administration in brown adipose tissue and white adipose tissue [57]. As a result, activation of TGR 5 and FXR by bile acid can regu- late intestinal signaling for host energy metabolism. Furthermore, the composition of bile acid is associated with gut microbiota and diet.

\section{Other metabolites contributing host energy metabolism}

Various metabolites other than SCFAs and bile acids can be produced by gut microbiota. Trimethylamine $\mathrm{N}$-oxide (TMAO), which is converted from carnitine or lecithin by gut microbiota, is a risk factor for cardiovascular disease [60]. The lipopolysaccharide (or endotoxin), which is produced from gram-negative bacteria, promotes adiposity resulting obesity via low-grade inflammation [61]. The absorbed TMAO induces hyperglycemia by activating protein kinase R-like endoplasmic reticulum kinase (PERK) [62]. Methane which produced by methanogens such as Methanobrevibacter smithii may modulate host energy balance via conversion of hydrogen to methane gas [63]. In addition, the high concentration of plasma indolepropionic acid (IPA) which is produced from tryptophan by gut microbiota, is associated with the lower risk factor of type 2 diabetes mellitus in human [64], and plasma glucose is decreased in IPA-fed mice [65]. Moreover, succinate, which is one of gut microbial metabolites from dietary fiber, improves host glucose homeostasis via induction of IGN as a glucose precursor [66]. Therefore, gut microbiota-producing metabolites can be absorbed through the intestines, which can have an influence on the metabolism of the whole body.

\section{THE COMPETITION OF BACTERIA AND HOST FOR ENERGY HARVEST}

Gut microbiota consume nutrients for energy first because the gut microbiota and the host share nutrients (Fig. 1). Consequently, the gut microbiota and the host can be in competition for absorption of the same energy sources (e.g., sugar, fat, and protein). This means that the energy absorption into the host can be restricted by specific bacteria even though the appropriate nutritional content is supplied by the hosts diet. Moreover, metabolic diseases are linked to increased intestinal permeability and translocation of bacteria [67]. Diet composition is also highly linked with the proportion of gut microbiota and the diet source can directly change gut microbiota composition in human $[68,69]$, and the altered microbiota contribute to an enhanced harvest of energy from the hosts diet in patients with obesity and metabolic diseases [12,70]. 
Host and microbiota competition in dietary energy harvest Recently, we reported a study suggesting that an increased Firmicutes to Bacteroidetes ratio is not necessarily associated with an increase in intestinal energy harvest and obesity [69]. This study was designed to address the question of whether the increased Firmicutes is the cause or the consequence of obesity. By using the common probiotic bacteria, Lactobacillus rhamnosus GG (LGG), and a quantitative tracing method with isotope tracers, we showed that the anti-obesity effect of the probiotic bacteria is due to the bacterial-host competition for intestinal energy sources rather the phylum composition. Furthermore, the increase of these specific gut bacteria, which consume dietary substrates results in a decrease in the remaining nutrients in which, in turn, can reduce the amount of nutrients that can be absorbed by the host. Lactobacillus bacteria consume fatty acids during cultivation and delay the intestinal absorption of oleic acids in high-fat diet-fed mice [71]. Chronic oral administration of Lactobacillus reduced weight gain, body fat mass, and hepatic lipid accumulation during high-fat diet feeding, without altering dietary calorie intake or fecal calorie excretion [71]. Pyrosequencing data show that the ratio of Firmicutes to Bacteroidetes is unchanged by LGG treatment, despite the dramatic changes in metabolic phenotypes [71]. Another study also suggests a similar result and shows that Lactobacillus strains reduce intestinal free fatty acids, resulting in a loss of body weight [72]. It is important to note that the Lactobacillus species are the most widely used probiotics and belong to the phylum Firmicutes [73]. Probiotics are thought to confer health benefits against metabolic diseases including obesity [74] and NAFLD [75,76]. Moreover, Lactobacillus strains can use exogenous fatty acids to increase their survival in acidic conditions [77]. Therefore, the metabolic phenotypes from probiotic Lactobacillus belonged to Firmicutes would be worsen by colonizing these bacteria to intestine if the metabolic disease status can simply be estimated by the increased ratio of Firmicutes to Bacteroidetes.

Furthermore, Bacteroidetes is known to be the major bacterium producing acetate $(\mathrm{C} 2)$ and propionate $(\mathrm{C} 3)$ in the intestine, which can induce glucose-stimulated insulin secretion and insulin resistance through activation of the parasympathetic nerve system and lipogenesis [50,78]. Firmicutes strains are known to mainly produce butyrate (C4), which improves insulin resistance by inhibiting histone deacetylase $[79,80]$. Given the health benefits of Lactobacillus in relation to metabolic diseases, an increase in Firmicutes due to a high-fat diet, particularly the increase in Lactobacillus, is likely to shift substrate-preferences secondary to the increased dietary lipid supply rather than cause obesity. Taken together, all above studies suggest that the assumption of bacterial contribution in host metabolic diseases has no consistency yet in the view of bacterial phylum composition, and further studies should be elucidated.

\section{CONCLUSION}

Since the initial findings of an association between bacterial phylum composition and obesity, a number of studies have examined the phylum-level patterns in relation to metabolic diseases including obesity, NAFLD, and diabetes. However, the results are not ubiquitous, and debate has remained whether alterations in the composition of the gut microbiota are the cause of consequence of metabolic diseases. More specifically, over the phylum-level, individual species level of gut bacteria should be studied to investigate which specific bacteria can affect the development of metabolic diseases. Moreover, gut bacteria are highly diverse due to their ability to relocate and their metabolic responses to different environments (e.g., diet, cold temperature, and antibiotics). Thus, the bacteria themselves need to be studied in further detail including their response to the environment as well as the profiles of metabolites produced and the characteristics of substrate preference regarding energy metabolism.

\section{CONFLICTS OF INTEREST}

No potential conflict of interest relevant to this article was reported.

\section{ORCID}

Yeonmi Lee https://orcid.org/0000-0003-4993-7972

Hui-Young Lee https://orcid.org/0000-0002-3464-6382

\section{ACKNOWLEDGMENTS}

This study was supported by the Bio \& Medical Technology Development Program of the National Research Foundation (NRF) funded by the Korean government (MSIT) (NRF-2018M3A9F3056405). 


\section{REFERENCES}

1. Human Microbiome Project Consortium. Structure, function, and diversity of the healthy human microbiome. Nature 2012; 486:207-14

2. Sender R, Fuchs S, Milo R. Are we really vastly outnumbered? Revisiting the ratio of bacterial to host cells in humans. Cell 2016;164:337-40.

3. Sender R, Fuchs S, Milo R. Revised estimates for the number of human and bacteria cells in the body. PLoS Biol 2016;14: e1002533.

4. Gill SR, Pop M, Deboy RT, Eckburg PB, Turnbaugh PJ, Samuel BS, Gordon JI, Relman DA, Fraser-Liggett CM, Nelson KE. Metagenomic analysis of the human distal gut microbiome. Science 2006;312:1355-9.

5. Ley RE, Turnbaugh PJ, Klein S, Gordon JI. Microbial ecology: human gut microbes associated with obesity. Nature 2006;444: 1022-3.

6. Cani PD, Van Hul M, Lefort C, Depommier C, Rastelli M, Everard A. Microbial regulation of organismal energy homeostasis. Nat Metab 2019;1:34-46.

7. Peters BA, Shapiro JA, Church TR, Miller G, Trinh-Shevrin C, Yuen E, Friedlander C, Hayes RB, Ahn J. A taxonomic signature of obesity in a large study of American adults. Sci Rep 2018;8:9749.

8. Million M, Maraninchi M, Henry M, Armougom F, Richet H, Carrieri P, Valero R, Raccah D, Vialettes B, Raoult D. Obesityassociated gut microbiota is enriched in Lactobacillus reuteri and depleted in Bifidobacterium animalis and Methanobrevibacter smithii. Int J Obes (Lond) 2012;36:817-25.

9. Duncan SH, Lobley GE, Holtrop G, Ince J, Johnstone AM, Louis P, Flint HJ. Human colonic microbiota associated with diet, obesity and weight loss. Int J Obes (Lond) 2008;32:1720-4.

10. Wang B, Jiang X, Cao M, Ge J, Bao Q, Tang L, Chen Y, Li L. Altered fecal microbiota correlates with liver biochemistry in nonobese patients with non-alcoholic fatty liver disease. Sci Rep 2016;6:32002.

11. Spiegelman BM, Flier JS. Obesity and the regulation of energy balance. Cell 2001;104:531-43.

12. Cani PD, Delzenne NM. Interplay between obesity and associated metabolic disorders: new insights into the gut microbiota. Curr Opin Pharmacol 2009;9:737-43.

13. Wang B, Yao M, Lv L, Ling Z, Li L. The human microbiota in health and disease. Engineering 2017;3:71-82.

14. Cummings JH, Macfarlane GT. Role of intestinal bacteria in nutrient metabolism. JPEN J Parenter Enteral Nutr 1997;21: 357-65.

15. McNeil NI. The contribution of the large intestine to energy supplies in man. Am J Clin Nutr 1984;39:338-42.

16. Cummings JH. Short chain fatty acids in the human colon. Gut 1981;22:763-79.

17. Popkin BM. Global nutrition dynamics: the world is shifting rapidly toward a diet linked with noncommunicable diseases. Am J Clin Nutr 2006;84:289-98.

18. Cebra JJ. Influences of microbiota on intestinal immune system development. Am J Clin Nutr 1999;69:1046S-51S.

19. Macfarlane GT, Macfarlane S. Human colonic microbiota: ecology, physiology and metabolic potential of intestinal bacteria. Scand J Gastroenterol Suppl 1997;222:3-9.

20. Backhed F, Ding H, Wang T, Hooper LV, Koh GY, Nagy A, Semenkovich CF, Gordon JI. The gut microbiota as an environmental factor that regulates fat storage. Proc Natl Acad Sci U S A 2004;101:15718-23.

21. Turnbaugh PJ, Ley RE, Mahowald MA, Magrini V, Mardis ER, Gordon JI. An obesity-associated gut microbiome with increased capacity for energy harvest. Nature 2006;444:1027-31.

22. Ley RE, Backhed F, Turnbaugh P, Lozupone CA, Knight RD, Gordon JI. Obesity alters gut microbial ecology. Version 2. Proc Natl Acad Sci U S A 2005;102:11070-5.

23. Hildebrandt MA, Hoffmann C, Sherrill-Mix SA, Keilbaugh SA, Hamady M, Chen YY, Knight R, Ahima RS, Bushman F, Wu GD. High-fat diet determines the composition of the murine gut microbiome independently of obesity. Gastroenterology 2009;137:1716-24.

24. Mouzaki M, Comelli EM, Arendt BM, Bonengel J, Fung SK, Fischer SE, McGilvray ID, Allard JP. Intestinal microbiota in patients with nonalcoholic fatty liver disease. Hepatology 2013; 58:120-7.

25. Turnbaugh PJ, Backhed F, Fulton L, Gordon JI. Diet-induced obesity is linked to marked but reversible alterations in the mouse distal gut microbiome. Cell Host Microbe 2008;3:213-23.

26. Guo X, Xia X, Tang R, Zhou J, Zhao H, Wang K. Development of a real-time PCR method for Firmicutes and Bacteroidetes in faeces and its application to quantify intestinal population of obese and lean pigs. Lett Appl Microbiol 2008;47:367-73.

27. Sonnenburg ED, Zheng H, Joglekar P, Higginbottom SK, Firbank SJ, Bolam DN, Sonnenburg JL. Specificity of polysaccharide use in intestinal bacteroides species determines diet-induced microbiota alterations. Cell 2010;141:1241-52.

28. Zmora N, Suez J, Elinav E. You are what you eat: diet, health and 
the gut microbiota. Nat Rev Gastroenterol Hepatol 2019;16:3556.

29. Sonnenburg JL, Backhed F. Diet-microbiota interactions as moderators of human metabolism. Nature 2016;535:56-64.

30. Zhu L, Baker SS, Gill C, Liu W, Alkhouri R, Baker RD, Gill SR. Characterization of gut microbiomes in nonalcoholic steatohepatitis (NASH) patients: a connection between endogenous alcohol and NASH. Hepatology 2013;57:601-9.

31. Loomba R, Seguritan V, Li W, Long T, Klitgord N, Bhatt A, Dulai PS, Caussy C, Bettencourt R, Highlander SK, Jones MB, Sirlin CB, Schnabl B, Brinkac L, Schork N, Chen CH, Brenner DA, Biggs W, Yooseph S, Venter JC, Nelson KE. Gut microbiome-based metagenomic signature for non-invasive detection of advanced fibrosis in human nonalcoholic fatty liver disease. Cell Metab 2017;25:1054-62.

32. Brown CT, Davis-Richardson AG, Giongo A, Gano KA, Crabb DB, Mukherjee N, Casella G, Drew JC, Ilonen J, Knip M, Hyoty H, Veijola R, Simell T, Simell O, Neu J, Wasserfall CH, Schatz D, Atkinson MA, Triplett EW. Gut microbiome metagenomics analysis suggests a functional model for the development of autoimmunity for type 1 diabetes. PLoS One 2011;6:e25792.

33. Larsen N, Vogensen FK, van den Berg FW, Nielsen DS, Andreasen AS, Pedersen BK, Al-Soud WA, Sorensen SJ, Hansen LH, Jakobsen M. Gut microbiota in human adults with type 2 diabetes differs from non-diabetic adults. PLoS One 2010;5: e9085.

34. Suez J, Korem T, Zeevi D, Zilberman-Schapira G, Thaiss CA, Maza O, Israeli D, Zmora N, Gilad S, Weinberger A, Kuperman Y, Harmelin A, Kolodkin-Gal I, Shapiro H, Halpern Z, Segal E, Elinav E. Artificial sweeteners induce glucose intolerance by altering the gut microbiota. Nature 2014;514:181-6.

35. Everard A, Belzer C, Geurts L, Ouwerkerk JP, Druart C, Bindels LB, Guiot Y, Derrien M, Muccioli GG, Delzenne NM, de Vos WM, Cani PD. Cross-talk between Akkermansia muciniphila and intestinal epithelium controls diet-induced obesity. Proc Natl Acad Sci U S A 2013;110:9066-71.

36. Shin NR, Lee JC, Lee HY, Kim MS, Whon TW, Lee MS, Bae JW. An increase in the Akkermansia spp. population induced by metformin treatment improves glucose homeostasis in dietinduced obese mice. Gut 2014;63:727-35.

37. Kondo T, Kishi M, Fushimi T, Kaga T. Acetic acid upregulates the expression of genes for fatty acid oxidation enzymes in liver to suppress body fat accumulation. J Agric Food Chem 2009; 57:5982-6.

38. Yamashita H, Fujisawa K, Ito E, Idei S, Kawaguchi N, Kimoto
M, Hiemori M, Tsuji H. Improvement of obesity and glucose tolerance by acetate in type 2 diabetic Otsuka Long-Evans Tokushima Fatty (OLETF) rats. Biosci Biotechnol Biochem 2007;71:1236-43.

39. Kimura I, Ozawa K, Inoue D, Imamura T, Kimura K, Maeda T, Terasawa K, Kashihara D, Hirano K, Tani T, Takahashi T, Miyauchi S, Shioi G, Inoue H, Tsujimoto G. The gut microbiota suppresses insulin-mediated fat accumulation via the shortchain fatty acid receptor GPR43. Nat Commun 2013;4:1829.

40. Ge H, Li X, Weiszmann J, Wang P, Baribault H, Chen JL, Tian $\mathrm{H}$, Li Y. Activation of G protein-coupled receptor 43 in adipocytes leads to inhibition of lipolysis and suppression of plasma free fatty acids. Endocrinology 2008;149:4519-26.

41. Perry RJ, Borders CB, Cline GW, Zhang XM, Alves TC, Petersen KF, Rothman DL, Kibbey RG, Shulman GI. Propionate increases hepatic pyruvate cycling and anaplerosis and alters mitochondrial metabolism. J Biol Chem 2016;291:12161-70.

42. De Vadder F, Kovatcheva-Datchary P, Goncalves D, Vinera J, Zitoun C, Duchampt A, Backhed F, Mithieux G. Microbiotagenerated metabolites promote metabolic benefits via gutbrain neural circuits. Cell 2014;156:84-96.

43. Gao Z, Yin J, Zhang J, Ward RE, Martin RJ, Lefevre M, Cefalu WT, Ye J. Butyrate improves insulin sensitivity and increases energy expenditure in mice. Diabetes 2009;58:1509-17.

44. Hong J, Jia Y, Pan S, Jia L, Li H, Han Z, Cai D, Zhao R. Butyrate alleviates high fat diet-induced obesity through activation of adiponectin-mediated pathway and stimulation of mitochondrial function in the skeletal muscle of mice. Oncotarget 2016; 7:56071-82.

45. Jia Y, Hong J, Li H, Hu Y, Jia L, Cai D, Zhao R. Butyrate stimulates adipose lipolysis and mitochondrial oxidative phosphorylation through histone hyperacetylation-associated $\beta 3$ adrenergic receptor activation in high-fat diet-induced obese mice. Exp Physiol 2017;102:273-81.

46. Torres-Fuentes C, Schellekens H, Dinan TG, Cryan JF. The microbiota-gut-brain axis in obesity. Lancet Gastroenterol Hepatol 2017;2:747-56.

47. Bliss ES, Whiteside E. The gut-brain axis, the human gut microbiota and their integration in the development of obesity. Front Physiol 2018;9:900.

48. Chambers ES, Viardot A, Psichas A, Morrison DJ, Murphy KG, Zac-Varghese SE, MacDougall K, Preston T, Tedford C, Finlayson GS, Blundell JE, Bell JD, Thomas EL, Mt-Isa S, Ashby D, Gibson GR, Kolida S, Dhillo WS, Bloom SR, Morley W, Clegg S, Frost G. Effects of targeted delivery of propionate to the hu- 
man colon on appetite regulation, body weight maintenance and adiposity in overweight adults. Gut 2015;64:1744-54.

49. Frost G, Sleeth ML, Sahuri-Arisoylu M, Lizarbe B, Cerdan S, Brody L, Anastasovska J, Ghourab S, Hankir M, Zhang S, Carling D, Swann JR, Gibson G, Viardot A, Morrison D, Louise Thomas E, Bell JD. The short-chain fatty acid acetate reduces appetite via a central homeostatic mechanism. Nat Commun 2014;5:3611.

50. Perry RJ, Peng L, Barry NA, Cline GW, Zhang D, Cardone RL, Petersen KF, Kibbey RG, Goodman AL, Shulman GI. Acetate mediates a microbiome-brain- $\beta$-cell axis to promote metabolic syndrome. Nature 2016;534:213-7.

51. Strandwitz P, Kim KH, Terekhova D, Liu JK, Sharma A, Levering J, McDonald D, Dietrich D, Ramadhar TR, Lekbua A, Mroue N, Liston C, Stewart EJ, Dubin MJ, Zengler K, Knight R, Gilbert JA, Clardy J, Lewis K. GABA-modulating bacteria of the human gut microbiota. Nat Microbiol 2019;4:396-403.

52. Kaelberer MM, Buchanan KL, Klein ME, Barth BB, Montoya MM, Shen X, Bohorquez DV. A gut-brain neural circuit for nutrient sensory transduction. Science 2018;361:eaat5236.

53. Fulling C, Dinan TG, Cryan JF. Gut microbe to brain signaling: what happens in vagus.... Neuron 2019;101:998-1002.

54. Redinger RN. The coming of age of our understanding of the enterohepatic circulation of bile salts. Am J Surg 2003;185:16872.

55. Reddy BS. Diet and excretion of bile acids. Cancer Res 1981;41 (9 Pt 2):3766-8.

56. Islam KB, Fukiya S, Hagio M, Fujii N, Ishizuka S, Ooka T, Ogura Y, Hayashi T, Yokota A. Bile acid is a host factor that regulates the composition of the cecal microbiota in rats. Gastroenterology 2011;141:1773-81.

57. Watanabe M, Houten SM, Mataki C, Christoffolete MA, Kim BW, Sato H, Messaddeq N, Harney JW, Ezaki O, Kodama T, Schoonjans K, Bianco AC, Auwerx J. Bile acids induce energy expenditure by promoting intracellular thyroid hormone activation. Nature 2006;439:484-9.

58. Iguchi Y, Yamaguchi M, Sato H, Kihira K, Nishimaki-Mogami T, Une M. Bile alcohols function as the ligands of membranetype bile acid-activated $\mathrm{G}$ protein-coupled receptor. J Lipid Res 2010;51:1432-41.

59. Zhang Y, Lee FY, Barrera G, Lee H, Vales C, Gonzalez FJ, Willson TM, Edwards PA. Activation of the nuclear receptor FXR improves hyperglycemia and hyperlipidemia in diabetic mice. Proc Natl Acad Sci U S A 2006;103:1006-11.

60. Kanitsoraphan C, Rattanawong P, Charoensri S, Senthong V.
Trimethylamine N-oxide and risk of cardiovascular disease and mortality. Curr Nutr Rep 2018;7:207-13.

61. Zhao L. The gut microbiota and obesity: from correlation to causality. Nat Rev Microbiol 2013;11:639-47.

62. Chen S, Henderson A, Petriello MC, Romano KA, Gearing M, Miao J, Schell M, Sandoval-Espinola WJ, Tao J, Sha B, Graham M, Crooke R, Kleinridders A, Balskus EP, Rey FE, Morris AJ, Biddinger SB. Trimethylamine N-oxide binds and activates PERK to promote metabolic dysfunction. Cell Metab 2019;30: 1141-51.

63. Mathur R, Kim G, Morales W, Sung J, Rooks E, Pokkunuri V, Weitsman S, Barlow GM, Chang C, Pimentel M. Intestinal Methanobrevibacter smithii but not total bacteria is related to diet-induced weight gain in rats. Obesity (Silver Spring) 2013; 21:748-54.

64. de Mello VD, Paananen J, Lindström J, Lankinen MA, Shi L, Kuusisto J, Pihlajamaki J, Auriola S, Lehtonen M, Rolandsson O, Bergdahl IA, Nordin E, Ilanne-Parikka P, Keinanen-Kiukaanniemi S, Landberg R, Eriksson JG, Tuomilehto J, Hanhineva K, Uusitupa M. Indolepropionic acid and novel lipid metabolites are associated with a lower risk of type 2 diabetes in the Finnish Diabetes Prevention Study. Sci Rep 2017;7:46337.

65. Abildgaard A, Elfving B, Hokland M, Wegener G, Lund S. The microbial metabolite indole-3-propionic acid improves glucose metabolism in rats, but does not affect behaviour. Arch Physiol Biochem 2018;124:306-12.

66. De Vadder F, Kovatcheva-Datchary P, Zitoun C, Duchampt A, Backhed F, Mithieux G. Microbiota-produced succinate improves glucose homeostasis via intestinal gluconeogenesis. Cell Metab 2016;24:151-7.

67. Bischoff SC, Barbara G, Buurman W, Ockhuizen T, Schulzke JD, Serino M, Tilg H, Watson A, Wells JM. Intestinal permeability: a new target for disease prevention and therapy. BMC Gastroenterol 2014;14:189.

68. David LA, Maurice CF, Carmody RN, Gootenberg DB, Button JE, Wolfe BE, Ling AV, Devlin AS, Varma Y, Fischbach MA, Biddinger SB, Dutton RJ, Turnbaugh PJ. Diet rapidly and reproducibly alters the human gut microbiome. Nature 2014;505: 559-63.

69. Singh RK, Chang HW, Yan D, Lee KM, Ucmak D, Wong K, Abrouk M, Farahnik B, Nakamura M, Zhu TH, Bhutani T, Liao W. Influence of diet on the gut microbiome and implications for human health. J Transl Med 2017;15:73.

70. Tremaroli V, Backhed F. Functional interactions between the gut microbiota and host metabolism. Nature 2012;489:242-9. 
71. Jang HR, Park HJ, Kang D, Chung H, Nam MH, Lee Y, Park $\mathrm{JH}$, Lee HY. A protective mechanism of probiotic Lactobacillus against hepatic steatosis via reducing host intestinal fatty acid absorption. Exp Mol Med 2019;51:1-14.

72. Chung HJ, Yu JG, Lee IA, Liu MJ, Shen YF, Sharma SP, Jamal MA, Yoo JH, Kim HJ, Hong ST. Intestinal removal of free fatty acids from hosts by Lactobacilli for the treatment of obesity. FEBS Open Bio 2016;6:64-76.

73. Segers ME, Lebeer S. Towards a better understanding of Lactobacillus rhamnosus GG: host interactions. Microb Cell Fact 2014;13 Suppl 1(Suppl 1):S7.

74. Sanders ME. Probiotics: definition, sources, selection, and uses. Clin Infect Dis 2008;46 Suppl 2:S58-61.

75. Ritze Y, Bardos G, Claus A, Ehrmann V, Bergheim I, Schwiertz A, Bischoff SC. Lactobacillus rhamnosus GG protects against nonalcoholic fatty liver disease in mice. PLoS One 2014;9:e80169.

76. Xin J, Zeng D, Wang H, Ni X, Yi D, Pan K, Jing B. Preventing non-alcoholic fatty liver disease through Lactobacillus johnsonii BS15 by attenuating inflammation and mitochondrial injury and improving gut environment in obese mice. Appl Microbiol Biotechnol 2014;98:6817-29.

77. Corcoran BM, Stanton C, Fitzgerald GF, Ross RP. Growth of probiotic lactobacilli in the presence of oleic acid enhances subsequent survival in gastric juice. Microbiology 2007;153(Pt 1):291-9.

78. Macfarlane S, Macfarlane GT. Regulation of short-chain fatty acid production. Proc Nutr Soc 2003;62:67-72.

79. Vrieze A, Van Nood E, Holleman F, Salojarvi J, Kootte RS, Bartelsman JF, Dallinga-Thie GM, Ackermans MT, Serlie MJ, Oozeer R, Derrien M, Druesne A, Van Hylckama Vlieg JE, Bloks VW, Groen AK, Heilig HG, Zoetendal EG, Stroes ES, de Vos WM, Hoekstra JB, Nieuwdorp M. Transfer of intestinal microbiota from lean donors increases insulin sensitivity in individuals with metabolic syndrome. Gastroenterology 2012;143: 913-6.

80. Bouter K, Bakker GJ, Levin E, Hartstra AV, Kootte RS, Udayappan SD, Katiraei S, Bahler L, Gilijamse PW, Tremaroli V, Stahlman M, Holleman F, van Riel NAW, Verberne HJ, Romijn JA, Dallinga-Thie GM, Serlie MJ, Ackermans MT, Kemper EM, Willems van Dijk K, Backhed F, Groen AK, Nieuwdorp M. Differential metabolic effects of oral butyrate treatment in lean versus metabolic syndrome subjects. Clin Transl Gastroenterol 2018;9:155. 